\title{
Penetrating craniofacial trauma from a vice clamp: case report and discussion
}

\author{
Colleen Kjelland, BScN, MD*; Warren Thirsk, MD*
}

\section{ABSTRACT}

Penetrating craniofacial trauma, although uncommon, has a high potential for death or serious morbidity from injury to vital neurovascular structures. An in situ facial foreign body, particularly if large, presents significant challenges beyond safe and timely removal. Airway management, stabilization of the object, management of increased intracranial pressure, and identification of injuries to local structures are all issues that may require addressing. We present a case of penetrating facial trauma from a vice clamp, with an in situ foreign body, that illustrates several of these challenges and provides a forum for their discussion.

\section{RÉSUMÉ}

Le traumatisme craniofacial pénétrant, bien qu'il soit rare, présente un potentiel élevé de décès ou de morbidité grave en raison de l'atteinte aux structures neurovasculaires vitales. Un corps étranger in situ au niveau du visage, en particulier s'il est gros, présente des défis importants hormis son retrait sûr et en temps opportun. La prise en charge des voies respiratoires, la stabilisation de l'objet, la gestion de la pression intracrânienne accrue et la détermination de la présence de lésions aux structures locales sont autant de questions qui devront être résolues. Nous présentons un cas de traumatisme pénétrant au visage causé par un serre-joint, avec un corps étranger in situ, qui illustre plusieurs de ces défis et fournit un forum pour la discussion.

Keywords: craniofacial injury, facial injury, foreign body, maxillofacial injury, penetrating trauma

Penetrating craniofacial trauma, although uncommon, has a high potential for death or serious morbidity from injury to vital neurovascular structures. When an object remains embedded, additional issues arise, and careful assessment and management of any injuries and their sequelae, in consultation with appropriate surgi- cal services, are required to minimize morbidity and mortality.

We present a case of penetrating facial trauma from a vice clamp that remained in situ. Although the mechanism of injury is dramatic and rare, this case serves as an interesting illustration for emergency physicians of the issues surrounding airway management, assessment and treatment of traumatic threats to vision, and the anatomic structures at risk in penetrating craniofacial trauma.

\section{CASE REPORT}

A previously healthy 25-year-old man was working on a construction site when a metal vice clamp was accidently dropped from five storeys above him. He looked up in response to a shouted warning, and the handle of the clamp bypassed his helmet and eyeglasses to lodge in his face just under his left eye (Figure 1). There was no loss of consciousness and no other apparent injuries. Prehospital management consisted of spinal immobilization, stabilization of the clamp with tape, intravenous access, and analgesia administration. The patient was transported by fixed-wing air ambulance to our tertiary care facility.

On arrival, the patient was alert and oriented with normal vital signs and a patent, protected airway. The clamp was lodged at an approximately $60^{\circ}$ angle to the face and was extremely unstable, requiring manual support to maintain its position. There was minimal bleeding at the site of penetration and no tenderness of the cervical spine. Because of the risk of premature dislodgement of the clamp handle by gravity alone, spinal precautions were removed on clinical grounds so

From the *Department of Emergency Medicine, University of Alberta, Edmonton, AB.

Correspondence to: Dr. Colleen Kjelland, Kingsway Emergency Agency, Royal Alexandra Hospital, 541 CSC, 10240 Kingsway Avenue, Edmonton, AB T5H 3V9; cryan@ualberta.ca.

This article has been peer reviewed.

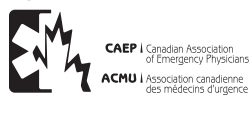




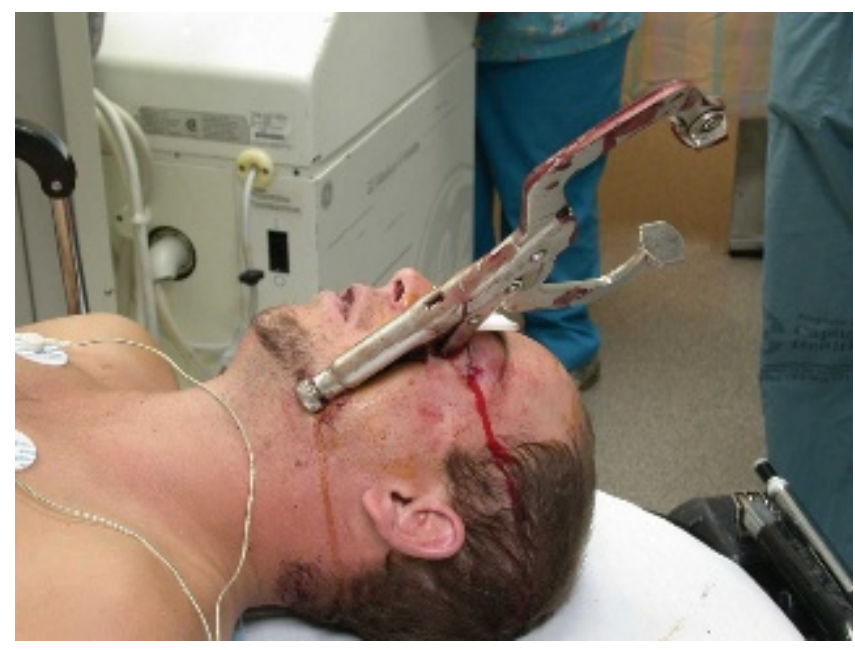

Figure 1. Patient on presentation to the emergency department with a vice clamp lodged in the left infraorbital region.

that the patient could reposition his head to help stabilize the clamp.

On secondary survey, the patient's left eye was proptotic with a tense, intact globe. He had difficulty with any extraocular movements of the left eye. His visual acuity in the left eye was reduced to movement only, and the pupil was miotic at $2 \mathrm{~mm}$ with weak constriction to light. Fundoscopy revealed papilledema on the left. The right eye had a normal pupil, fundoscopic examination, and visual acuity; however, there were also deficits in extraocular movements on the right, with the greatest limitation to abduction. Facial sensation was absent in both the left fifth cranial nerve V2 and right fifth cranial nerve V1 and V2 distributions. Skull radiographs (Figure 2) raised concern of intracranial penetration in addition to the obvious facial trauma.

During the course of his emergency department assessment, the patient became disoriented and increasingly restless and subsequently began to vomit repeatedly with secondary movement of the clamp whether sitting or rolled on his side to vomit.

A decision was made to intubate the patient to prevent inadvertent removal of the clamp and to ameliorate increases in intraocular and intracranial pressure associated with vomiting and motion. Although the clamp in his face made this a technically difficult intubation, the airway was otherwise judged to be normal. A bag-valve-mask (BVM) could be placed carefully beside the clamp with adequate seal for ventilation. While preparing for intubation, the patient was given $50 \mathrm{~g}$ of mannitol and $10 \mathrm{mg}$ of metoclopramide intravenously. Rapid sequence intubation (RSI)

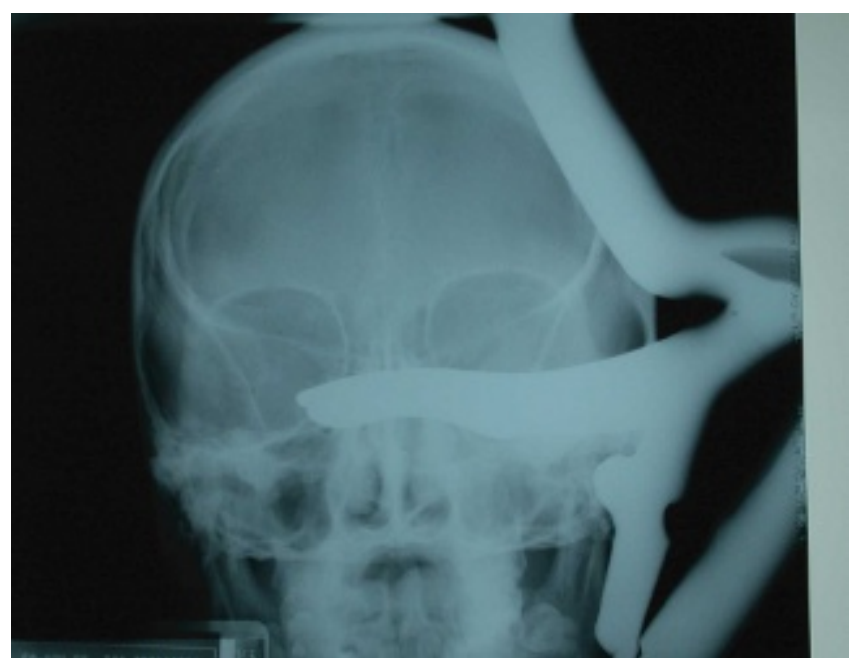

$\mathbf{A}$

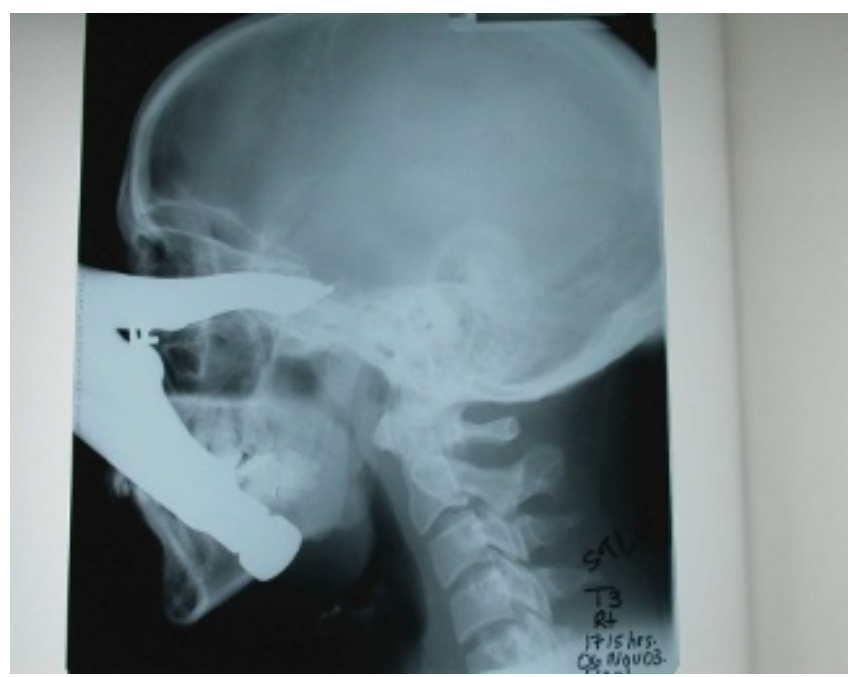

B

Figure 2. Anteroposterior (top) and lateral (bottom) skull radiographs with the vice clamp in situ.

was successfully performed with the patient's head at a $60^{\circ}$ angle to facilitate manual stabilization of the clamp.

After securing the airway, the next priority was assessing the left eye. Once reexamination of the eye confirmed an intact globe, intraocular pressure (IOP) was tested with a Tono-Pen tonometer (Reichert Ophthalmic Instruments, Depew, NY) and found to be $62 \mathrm{~mm} \mathrm{Hg}$. This elevated pressure, combined with the finding of proptosis and decreased visual acuity, indicated the need for an emergency canthotomy. With the assistance of Ophthalmology, a left lateral canthotomy was performed. Subsequent to this procedure, the IOP was found to have reduced to 32 $\mathrm{mm} \mathrm{Hg}$. 


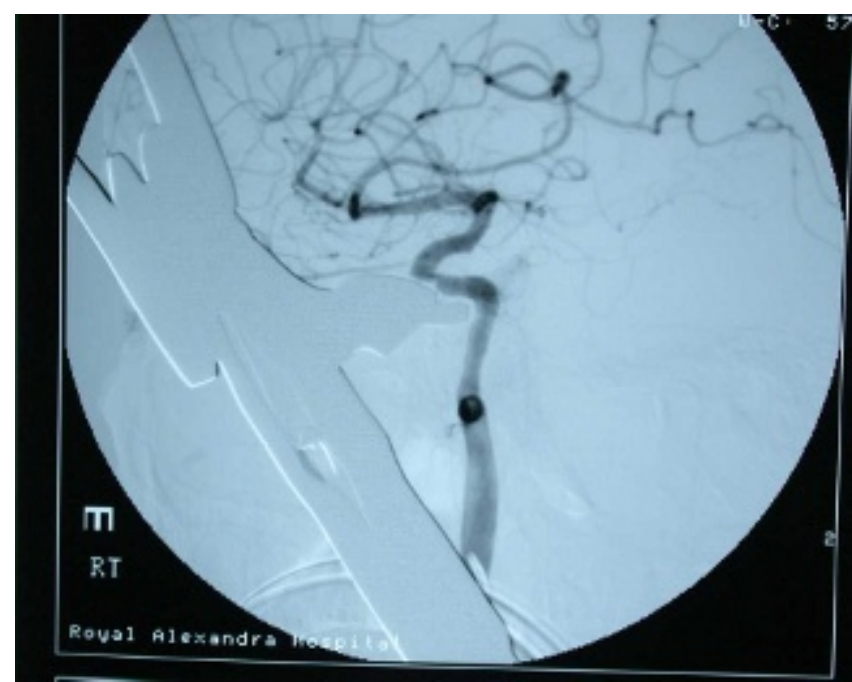

Figure 3. Angiogram with the vice clamp in situ showing a filling defect of the right internal carotid artery.

The trajectory of the clamp and the bilateral cranial nerve deficits on examination suggested penetration of the cavernous sinus across the midline and thus the potential for disruption of the internal carotid artery. Although a computed tomographic (CT) angiogram is often the best imaging modality for neurovascular injuries, the anticipated artifact created by the metal handle was felt to preclude its usefulness. Because of this, conventional angiography was undertaken, which revealed that the tip of the clamp had displaced the right internal carotid artery within the cavernous sinus and created a filling defect from either compression or penetration of the artery (Figure 3). Based on this, the neurosurgeon proceeded with a cut-down of the right internal carotid artery in the angiography suite to obtain proximal control of the vessel prior to removal of the clamp. The rationale for this decision was that it would facilitate early control if bleeding occurred on clamp removal, thus allowing more time if a craniotomy became necessary. The clamp was successfully removed, with no subsequent bleeding, and a repeat angiogram demonstrated an intact carotid artery with no filling defect or contrast leak.

A CT scan following the removal of the clamp showed comminuted fractures of the left orbital floor and left maxillary sinus and a basal skull fracture with shards of bone lodged in the right temporal lobe. Following the CT scan, the patient was taken to the intensive care unit and treated with seizure, tetanus, and antibiotic prophylaxis. He underwent surgery the next day to remove the bone fragments from his temporal lobe. His recovery was complicated by cerebral edema requiring intubation for several days and cerebrospinal fluid rhinorrhea requiring a second operation for dural patch placement.

The patient was discharged from hospital following recovery from the initial surgeries. He had several follow-up visits with Ophthalmology subsequent to this and has demonstrated good visual recovery in the left eye with an acuity of 20/50 and normal extraocular movements. Unfortunately, he has a persisting right cranial nerve VI palsy and partial cranial nerve III palsy, resulting in significant strabismus and a right Horner syndrome. He also has a moderate left enophthalmos secondary to the orbital floor fracture. Although he is back to full-time work, his persisting visual problems have restricted his work capabilities.

\section{DISCUSSION}

This case illustrates several basic yet important emergency management principles, from prehospital to definitive care, as they applied to an unusual presentation. Below we discuss the decisions that were made in this case regarding spinal immobilization, airway management, interventions for the proptotic eye, and investigations to define injury and facilitate safe removal of the foreign body removal.

From a prehospital management perspective, several important issues emerged. First, the decision regarding transfer to a trauma centre was made because of the numerous vital structures potentially involved and the anticipated need for surgical removal of the clamp. Tertiary transfer of a patient with penetrating head trauma is advised by the American College of Surgeons' guidelines for field triage in trauma. ${ }^{2}$ Second, the extent of our patient's injuries demonstrates the importance of prehospital stabilization of in situ foreign bodies for safe removal in hospital. Finally, the decision to apply cervical spine precautions must be evaluated on a case-by-case basis and sometimes must be balanced against the risk or downside of such immobilization. In this case, prehospital cervical spine immobilization was appropriate in the early stages of patient management given the uncertain clamp trajectory, as well as the fact that the patient had sustained a fall on impact. However, removal of these precautions on hospital arrival was supported by the alert and cooperative state of the patient, an otherwise normal spinal neurologic examination, and the evident upward 
angulation of the clamp away from the cervical spine. The potential benefits of continuation of cervical spine immobilization were carefully weighed against the apparent greater risk of additional damage to the cranial structures with clamp movement. Although there is little research specifically addressing cervical spine precautions in penetrating craniofacial injuries, a recent general review of cervical spine precautions in penetrating trauma suggests that in the absence of neurologic symptoms, the harm of immobilization may outweigh the benefit. ${ }^{3}$

Airway management in trauma patients has been well described, with RSI being the preferred method. ${ }^{4}$ However, for each patient, the risks and benefits of RSI must be weighed before a decision to use paralytics can be made. Relative contraindications to RSI in this case included concerns about the ability to BVM ventilate with a foreign body in situ, inability to extend the neck without dislodging the vice clamp, and immobilization of the head at an unusual angle. Although the presence of an in situ facial foreign body does not appear in standard lists of contraindications to RSI, it clearly must be considered during the decision of whether to use a paralytic agent. We chose to proceed with RSI in this case because of its benefit in reducing aspiration risk, its attenuation of increases in intraocular or intracranial pressure, and its lower likelihood of inadvertent movement of the clamp. ${ }^{5,6}$ Other intubation techniques, such as a blind technique, sedation only, or an awake intubation, were believed to pose a greater risk of aspiration, clamp dislodgement, or decreased first intubation success. ${ }^{4}$ Video-assisted techniques were not readily available at the time. We chose to preadminister lidocaine $(100 \mathrm{mg})$, a defasciculating dose of rocuronium $(5 \mathrm{mg})$, and fentanyl $(150 \mu \mathrm{g})$ to attempt to attenuate increases in intracranial and intraocular pressure with intubation, despite the lack of compelling evidence for this regimen. ${ }^{5}$ Propofol was used as the induction agent and has been shown to have a neuroprotective effect in brain-injured patients.

After the RSI, the next management priority was the increased IOP in the left eye. Although the clamp did not penetrate the globe, its position put the patient at risk of permanent vision loss in the left eye owing to increased pressure on the optic nerve. The constellation of proptosis, decreased visual acuity, and elevated IOP met the indications for a lateral canthotomy and cantholysis. ${ }^{1}$ It is likely that this ultimately saved our patient's vision.
Although most penetrating facial and cranial injuries occur from gunshot wounds, there are many examples in the literature of more unusual injuries and in situ foreign bodies. ${ }^{7-12}$ The finding of bilateral cranial nerve deficits in our patient was particularly significant as it suggested that the clamp had crossed the midline. A transcranial trajectory in penetrating injury has been identified as a predictor of increased morbidity and mortality. ${ }^{13}$ In our patient, most of the sequelae were in the right eye owing to cranial nerve deficits from the clamp crossing the midline.

Several neurovascular structures are within or in close proximity to the cavernous sinus, rendering each of them vulnerable to injury in this case given the trajectory of the clamp ${ }^{14}$ (Figure 4). The intracranial portion of the internal carotid artery is usually well protected, but in this case, the clamp handle could have led to fatal exsanguination or a cerebrovascular accident from either ischemia or emboli. Removal of foreign bodies with undetermined trajectories in close proximity to vital structures should generally be done only under the most controlled circumstances possible. ${ }^{10}$ Foreign bodies in situ can provide temporary tamponade of vascular injuries, and this possibility guided our approach to a delayed and controlled removal.

Structures within the cavernous sinus include the V1 and V2 branches of the fifth cranial nerve and the sixth cranial nerve or abducens nerve (see Figure 4). The abducens nerve is the most frequently injured cranial nerve from blunt trauma owing to its tortuous intracranial course..$^{15-17}$ In penetrating trauma, disruption at its ocular insertion point in the lateral rectus

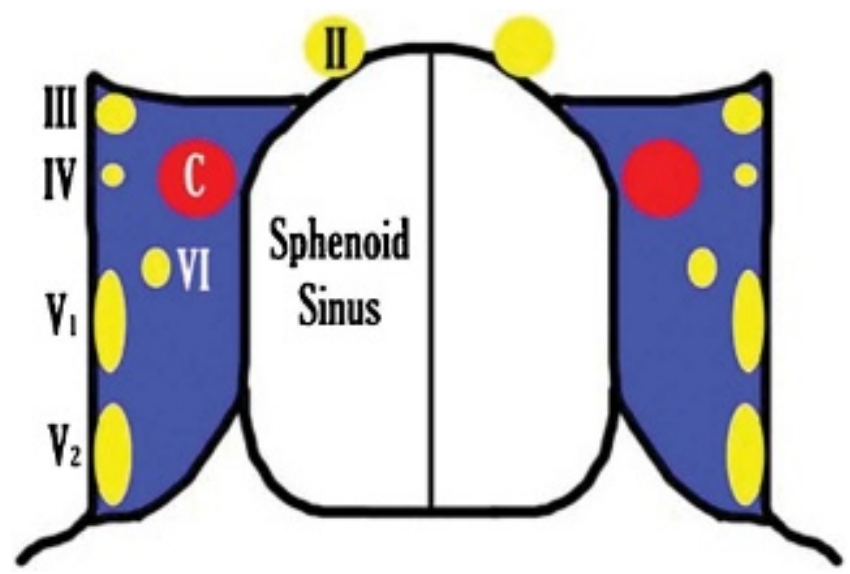

Figure 4. Anatomy of the cavernous sinus. $\mathrm{C}=$ carotid artery; II = second cranial nerve; III = third cranial nerve; IV = fourth cranial nerve; $\mathrm{V} 1$ and $\mathrm{V} 2$ = divisions 1 and 2 of the fifth cranial nerve. 
muscle is most common. In this case, the right sixth cranial nerve was transected within the cavernous sinus, leading to persistent extraocular deficits. The persisting Horner syndrome in the right eye was due to direct injury to the sympathetic chain adjacent to the internal carotid artery.

\section{CONCLUSION}

Penetrating facial and cranial injuries are associated with high morbidity and mortality. This case illustrates many of the challenges involved in the investigation, initial management, and safe removal of in situ facial foreign bodies.

Competing interests: None declared.

\section{REFERENCES}

1. McGinnes G, Howes D. Lateral canthotomy and cantholysis: a simple, vision-saving procedure. CFEM 2002;4:49-52.

2. Sasser SM, Hunt RC, Sullivent EE, et al. Guidelines for field triage of injured patients. Recommendations of the National Expert Panel on Field Triage. MMWR Recomm Rep 2009; 58(RR-1):1-35.

3. Haut ER, Kalish BT, Efron DT, et al. Spine immobilization in penetrating trauma: more harm than good? 7 Trauma 2010;68:115-21.

4. Nee PA, Benger J, Walls RM. Airway management. Emerg Med 7 2008;25:98-102.
5. Reynolds SF, Heffner J. Airway management of the critically ill patient: rapid sequence intubation (Critical Care Review). Chest 2005;127:1397-412.

6. Joly LM, Oswald AM, Disdet M, et al. Difficult endotracheal intubation as a result of penetrating cranio-facial injury by an arrow. Anesth Analg 2002;94:231-2.

7. Eidsness R, Coupal DJ, Kelly ME, et al. Traumatic orbital injury. 7 Trauma 2007;62:1286-7.

8. Eppley BL. Craniofacial impalement injury: a rake in the face. 7 Craniofac Surg 2002;13:35-7.

9. Hatton MP, Chen SH, Bernardino CR, et al. Trans-orbital foreign body with intracranial extension. 7 Trauma 2006;61: $752-4$.

10. Kaye K, Kilgore KP, Grorud C. Transoral crossbow injury: an unusual case of central nervous system foreign body. $\mathcal{F}$ Trauma 2004;57:653-5.

11. Sharma A, Pandey A, Diyora B, et al. Intracranial penetration of a glass piece through the temporal region in civilian head injury. 7 Trauma 2006;60:891-3.

12. Youssef AS, Morgan JM, Padhya T, et al. Penetrating craniofacial injury inflicted by a knife. 7 Trauma 2008;64: 1622-24.

13. Michael DB. Gunshot wounds to the head. Contemp Neurosurg 1995;17:1-5.

14. Netter FH. Atlas of human anatomy. 2nd ed. East Hanover, (NJ): Novartix; 1999.

15. Baker RS, Epstein AD. Ocular motor abnormalities from head trauma. Surv Ophthalmol 1991;35:245-64.

16. Celikoz B, Duman H, Selmanpakoglu N. Bilateral traumatic abducens palsy as a complication of a frontal-nasal-orbitalethmoidal fracture. 7 Oral Maxillofac Surg 1996;54:1471-4.

17. Holmes JM, Droste PJ, Beck RW. The natural history of acute traumatic sixth nerve palsy or paresis. 7 AAPOS 1998; $2: 265-8$. 